\title{
Atividade antibacteriana de Cereus jamacaru DC, Cactaceae
}

\author{
Aline Davet, Suzane Virtuoso, Josiane F. G. Dias, Marilis D. Miguel, \\ Andressa B. Oliveira, Obdúlio G. Miguel* \\ Departamento de Farmácia, Laboratório de Fitoquímica, Universidade Federal do Paraná, \\ Av. Prefeito Lothário Meissner 632, Jardim Botânico, 80210-170 Curitiba-PR, Brasil
}

\begin{abstract}
RESUMO: A procura por novos agentes antimicrobianos a partir de plantas vem sendo intensificada e não existem estudos direcionados à avaliação da atividade antimicrobiana de C. jamacaru frente a microrganismos prejudiciais ao homem. Em vista disso, avaliou-se o efeito antimicrobiano do extrato bruto etanólico do lenho (EBLE) e do córtex (EBCO) desta espécie frente a colônias puras de oito microrganismos patogênicos. Neste estudo foram utilizados os métodos difusão em ágar (meio sólido) e CIM (concentração inibitória mínima). Os resultados obtidos neste ensaio preliminar mostraram que EBCO apresentou atividade antimicrobiana mais pronunciada que EBCE e que os microrganismos cujo crescimento foi mais influenciado por EBCO foram Streptococcus epidermidis, Staphylococcus aureus, Pseudomonas aeruginosa e Escherichia coli.
\end{abstract}

Unitermos: Cereus jamacaru, Cactaceae, atividade antimicrobiana, concentração inibitória mínima.

\begin{abstract}
Screening antimicrobial activity of Cereus jamacaru DC, Cactaceae". The search for new antibiotic agents from plants is growing, and no study regarding the activity of $C$. jamacaru pathological microorganisms has been carried out. This research evaluates the antibiotic effect of crude ethanolic extracts of the cortex (EBCO) and wood (EBLE) of the species over eight microorganisms. Two methods were used: agar diffusion and MIC (minimal inhibitory concentration). EBCO showed better inhibition results than EBLE. Streptococcus epidermidis, Staphylococcus aureus, Pseudomonas aeruginosa and Escherichia coli are the microorganisms that were better inhibited by EBCO.
\end{abstract}

Keywords: Cereus jamacaru, antimicrobial activity, agar diffusion and minimal inhibitory concentration.

\section{INTRODUÇÃO}

As cactáceas apresentam grande potencial como fonte de substâncias de uso medicinal, cosmético e alimentício (Biavatti et al., 2007; Mariath et al., 2009). Muitos cactos possuem propriedades medicinais bem estabelecidas, como é o caso da espécie Opuntia ficusindica, que apresenta atividade antioxidante (Lee et al., 2002), antiinflamatória (Park et al., 2000) e antiulcerogênica (Galati et al., 2001).

Cereus jamacaru DC, Cactaceae, popularmente conhecido como mandacaru, é um cacto colunar característico da região semi-árida do Brasil. Para o gado, o uso justifica-se pela capacidade de armazenar grande quantidade de água (cerca de 15\%). A quantidade de proteína bruta chega a mais de $10 \%$ e o resíduo mineral a $10,66 \%$, dos quais $0,22 \%$ são em $\mathrm{P}_{2} \mathrm{O}_{5}$ e $5,61 \% \mathrm{em} \mathrm{CaO}$ (Braga, s.d.). O uso medicinal popular é pouco difundido; diz-se que as raízes e o caule são diuréticos e melhoram males do coração. Toda a planta é usada no combate ao escorbuto e nas afecções do aparelho respiratório - bronquites, tosse, catarro (Scheinvar, 1985). As raízes são utilizadas nas doenças respiratórias e renais, e como diuréticas (Agra et al., 2007 e Agra et al., 2008). Dentre as substâncias químicas identificadas no mandacaru está a tiramina, conhecida por sua atividade simpatomimética e provável responsável pela atividade cardiotônica (Brhun \& Lindgren, 1976).

Considerando o desafio que a descoberta de novos fármacos a partir de plantas, este trabalho teve como objetivo realizar uma avaliação preliminar do potencial antimicrobiano in vitro do extrato bruto etanólico de Cereus jamacaru e da substância isolada (tiramina) frente a culturas puras de algumas bactérias relacionadas à saúde humana.

\section{MATERIAL E MÉTODOS}

Os solventes utilizados para os procedimentos apresentavam grau de pureza analítico $\left(\mathrm{Merck}^{\circledR}\right)$. As suspensões bacterianas foram diluídas em solução salina estéril e foram padronizadas pela escala de MacFarland 
(tubo $0,5=0,5 \mathrm{~mL}$ de $\mathrm{BaCl}_{2} \cdot 2 \mathrm{H}_{2} \mathrm{O} 0,048 \mathrm{M}-1,75 \%(\mathrm{p} / \mathrm{V}$ ) em $99,5 \mathrm{~mL}$ de $\mathrm{H}_{2} \mathrm{SO}_{4} 0,36 \mathrm{~N}-1 \%(\mathrm{~V} / \mathrm{V})$. As culturas puras das bactérias (ATCC - American Type Culture Collection) e os discos de antibióticos usados como controle, cloranfenicol e cefalotina, foram adquiridos comercialmente $\left(\right.$ Newprov $\left.^{\circledR}\right)$. Os meios de cultura utilizados foram ágar Muller-Hinton para difusão em disco e caldo caseína de soja (CASOY) para o teste de concentração inibitória mínima - CIM.

\section{Material vegetal}

As hastes de Cereus jamacaru DC, Cactaceae, foram obtidas em janeiro de 2003 no Estado de Pernambuco, colhidas, secas e estabilizadas pela EMBRAPA SEMI-ÁRIDO na cidade de Petrolina. A identificação da espécie botânica foi realizada pela EMBRAPA e a exsicata está registrada no Museu Botânico desta entidade sob número 2299.

\section{Preparação do extrato bruto}

As hastes, secas e estabilizadas, foram separadas em quatro partes, das quais duas foram utilizadas neste estudo: cerne e córtex. Após a moagem, o material vegetal foi submetido à extração em etanol a $95 \%$ por soxhlet modificado (Carvalho, 2001) até esgotamento do material. Após extração, o extrato foi concentrado em evaporador rotatório sob pressão reduzida $\left(40{ }^{\circ} \mathrm{C}\right)$ para aproximadamente $1 / 5$ do seu volume, armazenado em frasco âmbar e conservado em freezer por um período de 24 horas, para precipitação de pigmentos. Após filtração a vácuo foram obtidos: extrato bruto etanólico de córtex e de lenho (EBCO e EBLE), respectivamente. EBLE com resíduo seco de $177,9 \mathrm{mg} / \mathrm{mL}$ e EBCO com 194,8 mg/ $\mathrm{mL}$.

\section{Solução de tiramina}

Foi preparada solução matriz de $1,0 \mathrm{mg} / \mathrm{mL}$ em água estéril, de onde foram feitas as diluições; as concentrações de tiramina/inóculo foram 1:1, 1:2, 1:4, 1:8, $1: 16,1: 32$ e 1:64, correspondendo a $1000,500,250,125$, $62,5,31,25$ e $15,625 \mu \mathrm{g} / \mathrm{mL}$ de tiramina, respectivamente. Estas concentrações foram escolhidas com base em concentrações dos padrões do ensaio (cloranfenicol e cefalotina).

\section{Ensaio biológico}

Para a realização do ensaio foram utilizados dois métodos: difusão em ágar de Kirby-Bauer adaptado por Romeiro(2001) e ConcentraçãoInibitória Mínima, segundo Koneman et al. (1993). Para ambos os testes, utilizaramse bactérias responsáveis por diversas enfermidades relacionadas ao homem: Streptococcus pyogenes
(ATCC19615), Streptococcus epidermidis (ATCC12228), Staphylococcus aureus (ATCC6538), Proteus mirabilis (ATCC43071), Pseudomonas aeruginosa (ATCC27283), Klebsiella pneumoniae (ATCC13883), Escherichia coli (ATCC11229) e Salmonella thyphimurium (ATCC14028). Para o preparo do inóculo, as culturas jovens de cada bactéria foram padronizadas em salina estéril segundo a escala 0,5 de MacFarland.

A tiramina foi testada apenas quanto à Concentração Inibitória Mínima.

\section{Difusão em ágar}

Os extratos brutos (EBCO e EBLE) foram impregnados em discos estéreis de papel $(6 \mathrm{~mm}$ de diâmetro) nas concentrações $100 \%, 50 \%, 25 \%$ e $12,5 \%$; as diluições foram feitas em etanol. Para cada disco foram usados $10 \mu \mathrm{L}$ de solução. Os discos foram levados a $40{ }^{\circ} \mathrm{C}$ e, depois de secos, espalhados em placa de Petri contendo o meio Ágar Mueller-Hinton. Como padrões utilizaram-se os antibióticos comerciais cloranfenicol 30 $\mu \mathrm{g}\left(\mathrm{Newprov}^{\circledR}\right)$ e cefalotina 30 $\mu \mathrm{g}\left(\mathrm{Newprov}^{\circledR}\right)$. Em cada placa foram colocados um disco de cada diluição, um apenas com etanol (branco) e os antibióticos. As placas foram incubadas em estufa a $35^{\circ} \mathrm{C}$ e os resultados foram lidos após 24 horas.

\section{Concentração inibitória mínima (CIM)}

Utilizaram-se $2 \mathrm{~mL}$ da suspensão de bactérias, em concentração padronizada com o tubo 0,5 da escala de MacFarland, para colocar em $100 \mathrm{~mL}(2 \%)$ de solução estéril de Tween $80^{\circledR}$ (a $2 \%$ em água destilada). Para o ensaio as amostras foram diluídas em caldo em concentrações decrescentes: 1:1, 1:2, 1:4, 1:8, 1:16, 1:32 e 1:64. Após as diluições, os tubos receberam $1 \mathrm{~mL}$ da suspensão de microrganismos em Tween $80^{\circledR}$. O controle negativo foi preparado com caldo e extrato 1:1 e o controle positivo com caldo e suspensão de bactérias 1:1. Os tubos foram incubados a $35^{\circ} \mathrm{C}$ por 24 horas e decorrido o tempo, procedeu-se às leituras.

\section{RESULTADOS E DISCUSSÃO}

Os resultados obtidos na avaliação preliminar da atividade antibacteriana do extrato bruto de córtex e lenho de Cereus jamacaru (Tabela 1), demonstraram potencial antibacteriano sobre o crescimento de todos os microrganismos testados, especialmente sobre Streptococcus epidermidis, Staphylococcus aureus, Pseudomonas aeruginosa e Escherichia coli, sobre cujos crescimentos o córtex apresentou maior inibição. Comparando-se os resultados obtidos pelos dois métodos, pode-se sugerir que as substâncias responsáveis pela atividade apresentam caráter predominantemente lipofílico. O ágar utilizado na difusão é particularmente 
hidrofílico, o que justificaria a não difusão dos extratos no meio. As cactáceas são reconhecidamente ricas em esteróides e estas substâncias podem estar relacionadas por parte da atividade antimicrobiana desta espécie.

Tabela 1. Resultados das médias dos halos de inibição (em mm) dos ensaios de atividade antibacteriana do EBCO, EBLE de $C$. jamacaru e tiramina.

\begin{tabular}{|c|c|c|c|c|c|c|c|c|c|}
\hline \multirow[t]{3}{*}{ C. jamacaru } & \multicolumn{9}{|c|}{ Difusão em ágar - Média do diâmetro dos halos de inibição em mm } \\
\hline & \multirow{2}{*}{ Concentrações } & \multirow[b]{2}{*}{$\mathrm{Sa}$} & \multirow[b]{2}{*}{$\mathrm{Sp}$} & \multirow[b]{2}{*}{$\mathrm{Se}$} & \multicolumn{3}{|c|}{ Microrganismos } & \multirow[b]{2}{*}{$\mathrm{Ec}$} & \multirow[b]{2}{*}{ St } \\
\hline & & & & & $\mathrm{Pm}$ & $\mathrm{Pa}$ & $\mathrm{Kp}$ & & \\
\hline \multirow[t]{4}{*}{ EBLE } & $100,0 \%$ & 0 & 0 & 0 & 0 & 0 & 0 & 0 & 0 \\
\hline & $50,0 \%$ & 0 & 0 & 0 & 0 & 0 & 0 & 0 & 0 \\
\hline & $25,0 \%$ & 0 & 0 & 0 & 0 & 0 & 0 & 0 & 0 \\
\hline & $12.5 \%$ & 0 & 0 & 0 & 0 & 0 & 0 & 0 & 0 \\
\hline \multirow[t]{4}{*}{ EBCO } & $100,0 \%$ & 0 & 0 & 0 & 0 & 0 & 0 & 0 & 0 \\
\hline & $50,0 \%$ & 0 & 0 & 0 & 0 & 0 & 0 & 0 & 0 \\
\hline & $25,0 \%$ & 0 & 0 & 0 & 0 & 0 & 0 & 0 & 0 \\
\hline & $12.5 \%$ & 0 & 0 & 0 & 0 & 0 & 0 & 0 & 0 \\
\hline \multicolumn{2}{|c|}{ Controle cloranfenicol $(30 \mu \mathrm{g} / \mathrm{mL})$} & 34 & 35 & 38 & 28 & 30 & 30 & 33 & 36 \\
\hline \multicolumn{2}{|c|}{ Controle cefalotina $(30 \mu \mathrm{g} / \mathrm{mL})$} & 50 & 45 & 40 & 11 & 0 & 26 & 0 & 29 \\
\hline \multicolumn{2}{|c|}{ Controle dos microrganismos } & + & + & + & + & + & + & + & + \\
\hline \multicolumn{2}{|c|}{ Controle do etanol } & 0 & 0 & 0 & 0 & 0 & 0 & 0 & 0 \\
\hline & & \multicolumn{8}{|c|}{ Concentração Inibitória Mínima (mg/mL) } \\
\hline \multirow[t]{2}{*}{ EBLE } & & 88,95 & 88,95 & 88,95 & 44,47 & 44,47 & 88,95 & 88,95 & 88,95 \\
\hline & & $(1: 1)$ & $(1: 1)$ & $(1: 1)$ & $(1: 2)$ & $(1: 2)$ & $(1: 1)$ & $(1: 1)$ & $(1: 1)$ \\
\hline \multirow[t]{3}{*}{ EBCO } & & 6,09 & 97,40 & 3,04 & 12,17 & 6,09 & 24,35 & 6,09 & 48,70 \\
\hline & & $(1: 16)$ & $(1: 1)$ & $(1: 32)$ & $(1: 8)$ & $(1: 16)$ & $(1: 4)$ & $(1: 16)$ & $(1: 2)$ \\
\hline & & \multicolumn{8}{|c|}{ Concentração Inibitória Mínima $(\mu \mathrm{g} / \mathrm{mL})$} \\
\hline \multirow{2}{*}{ Tiramina } & & 1000 & 1000 & 500 & 1000 & 1000 & 1000 & 1000 & 1000 \\
\hline & & $(1: 1)$ & $(1: 1)$ & $(1: 2)$ & $(1: 1)$ & $(1: 1)$ & $(1: 1)$ & $(1: 1)$ & $(1: 1)$ \\
\hline
\end{tabular}

Legenda: EBLE = extrato bruto etanólico de lenho; EBCO = extrato bruto etanólico de córtex; Sa = Staphylococcus aureus; Sp = Streptococcus pyogenes; $S e=$ Staphylococcus epidermidis; Pm = Proteus mirabilis; Pa = Pseudomonas aeruginosa; Kp =Klebsiella pneumoniae; $E c=$ Escherichia coli; $S t=$ Salmonella tiphymurium; $+=$ crescimento dos microrganismos em meio de cultura isento de droga.

Com relação a tiramina, pode-se observar que houve inibição do crescimento microbiano. No entanto, a concentração inibitória mínina da tiramina é muito alta, podendo significar que a inibição ocorreu por outros mecanismos que não os tradicionais (processos de inibição de síntese de ácidos nucléicos, de enzimas ou mesmo por alterações no $\mathrm{pH}$ do meio) como, por exemplo, a osmolaridade da solução (Korolkovas \& Burckhalter, 1988). Este resultado não indica ausência de atividade antimicrobiana, mas sim que o uso desta substância para fins terapêuticos seria inviável por ser necessária uma dose elevada para o efeito esperado. Além de existirem outras opções mais viáveis, as ações farmacológicas da tiramina sobre a liberação de catecolaminas são bastante conhecidas e poderia significar presença de efeito não desejado pronunciado (no caso do uso como antibacteriano).

Os resultados sugerem que as substâncias naturais presentes no extrato de mandacaru constituem perspectivas para a obtenção de antibióticos naturais.

\section{AGRADECIMENTOS}

Ao Dr. Viseldo da EMBRAPA, pela obtenção e identificação da espécie vegetal e ao TECPAR-PR, pelo fornecimento das culturas puras de bactérias utilizadas neste trabalho e a empresa As Ervas Curam Indústria Farmacêutica Ltda, pelo apoio financeiro e pela disponibilização de material para os ensaios. 


\section{REFERÊNCIAS}

Agra MJF, Freitas PF, Barbosa-Filho JM 2007. Synopsis of the plants known as medicinal and poisonous in Northeast of Brazil. Rev Bras Farmacogn 17: 114-140.

Agra MF, Silva KN, Basílio IJLD, Freitas PF, Barbosa-Filho JM 2008. Survey of medicinal plants used in the region Northeast of Brazil. Rev Bras Farmacogn 18: 472-508.

Biavatti M, Marensi V, Leite SN, Reis A 2007. Ethnopharmacognostic survey on botanical compendia for potential cosmeceutic species from Atlantic Forest. Rev Bras Farmacogn 17: 640-653.

Braga R [sd]. Plantas do Nordeste, Especialmente do Ceará. 4ed. Escola Superior de Agricultura de Mossoró: Editora Universitária da UFRN.

Brhun J, Lindgren J 1976. Cactaceae Alkaloids XXIII: alkaloids of Pachycereus pectin-aboriginum and Cereus jamacaru. Lloydia 39: 175-177.

Carvalho JLS 2001. Contribuição ao estudo fitoquímico e analitico de Nasturtium officinale R. BR., Brassicaceae. Curitiba. Dissertação de Mestrado em Ciências Farmacêuticas - Setor de Ciências da Saúde, Universidade Federal do Paraná.

Galati EM, Mendello MR, Giuffrida D, Miceli N 2001. Anticulcer activity of Opuntia ficus-indica (L.) Mill. (Cactaceae): ultra structural study. J Ethnopharmacol 76: 1-9.

Koneman EW, Allen SD, Dowwel JR VR, Sommers HM 1993. Diagnóstico microbiológico - texto e atlas colorido. 2.ed. São Paulo: Medicina Panamericana Editora do Brasil Ltda.

Korolkovas A, Burckhalter JH 1988. Química Farmacêutica. Rio de Janeiro: Editora Guanabara.

Lee JC, Kim HR, Kim J, Jam YM 2002. Antioxidant property of an ethanol extract of the stem of Opuntia ficus-indica var. saboten. J Agr Food Chem 50: 6490-696.

Mariath IR, Falcão HS, Barbosa-Filho JM, Sousa LCF, Tomaz ACA, Batista LM, Diniz MFFM, Athayde-Filho PF, Tavares JF, Silva MS, Cunha EVL 2009. Plants of the American continent with antimalarial activity. Rev Bras Farmacogn 19: 158-192.

Park E, Kahng J, Lee S, Shin K 2000. An anti-inflamatory principle from cactus. Fitoterapia 72: 288-290.

Romeiro RS 2001. Métodos em bacteriologia de plantas. Viçosa: Editora UFV.

Scheinvar L 1985. Cactáceas. Flora Ilustrada Catarinense, Itajaí. 